\title{
Supplier and Producer Profit Sharing Models Based on Inspection Sampling Policy
}

\author{
Chiuh-Cheng Chyu, I-Ping Huang
}

Department of Industrial Engineering and Management, Yuan-Ze University, Taiwan, China

Email: iehshsu@saturn.yzu.edu.tw

Received August 30 ${ }^{\text {th }}$, 2010; revised October $6^{\text {th }}$, 2010; accepted November $8^{\text {th }}, 2010$.

\begin{abstract}
This research presents three profit sharing models of a key item in a two-echelon supply chain production. The first model maximizes the supplier's profit while allowing the producer to take his own optimal inspection sampling policy. The second model is developed exclusively to the supplier's advantage. The last model adopts a collaborative strategy that permits both parties to negotiate an inspection policy, and aims to maximize total profit. In this two-echelon supply chain, the supplier determines the item quality by selecting a quality level of process setup, as well as the cycle time to reset this quality level. There is a tradeoff between total setup cost and the resulting quality of the key items. The interrupted geometric distribution is used to describe the item manufacturing quality for various cycle time setups. Furthermore, it is assumed that the inspection will not be perfect. The supplier must bear the loss from its downstream producer's type I inspection error, and the producer will in turn undertake the risk of selling flawed products to customers. The application of the proposed models is illustrated via an example with interrupted geometric distributions.
\end{abstract}

Keywords: Profit Sharing, Inspection Sampling Plans, Inspection Errors, Bayesian Approach, Interrupted Geometric Distributions

\section{Introduction}

Due to technological advancement, effective and efficient production is attainable by means of automated manufacturing in order to prevent human errors. However, production systems generally deteriorate due to different manners and terms of usage, which results in unstable production processes. Therefore, an appropriate inspection plan is essential to ensure product quality and reduce the production and the compensatory costs.

In 1975, Wetheril and Chiu proposed an inspection sampling plan that takes into account economic effects [1]. Bisgarrd et al. discussed a case when a failed product could be sold at a discount value [2]. Golhar brought forth a model considering the compensation of failed products sent to customers [3]. Moskowitz and Tang, Fink and Margavio, and Aminzadeh followed the aforementioned concept and established various sampling plans based on Bayesian approach [4-6].

The issue of quality level setting for product manufacturing processes has been extensively studied. The quality level setting and aging or deterioration rate of production facility will affect the process yield, which in turn engenders economic effect to the company. Lee and El- sayed and Lee et al. studied a profit maximization problem on quality level setting for filling processes [7,8]. Hsu et al. studied a multiple lot-sizing decision problem with an interrupted geometric yield [9]. The study describes a manufacturing process of drawing special steel coils. The drawing operation in the process involves a die that gradually becomes worn from use. The output will no longer meet specifications when the die wear is excessive, which implies that the integrated drawing process follows an interrupted geometric (IG) distribution. In such a production environment, selecting a high quality die and a short time replacement policy will result in high process yield; however, such quality setups will in turn be costly.

Yeh et al. considered that the deterioration of a production system can be classified into in-control or out-of-control states, and the elapsed time of the system in an in-control state is exponentially distributed [10]. Ben-Daya and Hariga and Moon et al. both investigated the economic lot scheduling problem with imperfect production processes by assuming the elapsed time shifts from an in-control state to an out-of- control state that is exponentially distributed $[11,12]$. Wang and Sheu deter- 
mined the optimal lot size with an assumption that the deteriorating production system has a geometric survival distribution under a free-repair warranty policy [13]. Wang obtained the optimal lot size by assuming the deteriorating production process has an increasing failure rate with a general shift distribution [14]. Other studies assumed that the number of conforming items in the imperfect production process has the following distributions: discrete uniform [15], binomial [16], and interrupted geometric [17-19].

This research presents three profit sharing models of a product involving a key item in a two-echelon supply chain process. The upstream supplier determines the quality level and cycle time setting of the key item production, while the downstream producer can select its own inspection sampling plan. It is assumed that the item manufacturing quality meets the interrupted geometric distribution, and inspection errors may occur. Bayesian approach is used to solve the two-echelon benefit problem by incorporating into the models the following factors: the supplier's item quality information, the producer's sampling information, inspection and product failure costs, and inspection accuracy. Finally, an example is provided to illustrate the features and applications of the models.

The remainder of the paper is organized as follows: Section 2 defines the problem and describes the model; Section 3 presents numerical results of two examples; Section 4 concludes this study.

\section{Problem and Models}

In this section, notations used throughout the paper are first introduced. The problem then is illustrated in Sub-Section 2.2 via a diagram. Finally, three profit sharing models and a sampling inspection plan are detailed in subsequent sections.

\subsection{Notations}

$x$ : a process quality level setting, $x \in \boldsymbol{X}$.

$\boldsymbol{X}$ : set of possible quality level settings.

$T$ : cycle time for resetting the process quality level.

$\Delta$ : set of all choices for cycle time $T$.

$S_{u}$ : selling price per item by supplier.

$C_{u}$ : manufacturing cost per item by supplier.

$C_{x}$ : setup cost for process quality level $x$.

$N$ : quantity ordered by producer.

$S_{d}$ : selling price per item by producer.

$D_{1}$ : producer's stage 1 decision for sample size $n$.

$q_{1}$ : probability of no type I error, a constant.

$q_{2}$ : probability of no type II error, a constant.

$P$ : process yield or probability that an item is good; a random variable.
$W$ : probability of an item being reported "good" during inspection.

$Y_{n}$ : number of reported "defective" items at stage $1 ; y$ is the realization.

$Z_{N-n}$ : number of defective items in the remainder of lot.

$Y_{N-n}$ : total number of reported "defective" items in the remainder of the lot after full inspection.

$k_{1}$ : inspection cost per item.

$k_{2}$ : penalty cost of a failed product sold to customers.

$M(y)$ : number of inspections to compensate $y$ reported as "defective" to producer.

$R(n)$ : number of defectives due to type II error for $n$ reported "good" items.

$D_{2}$ : producer's stage 2 decision on the remainder of the lot after observing the sampling outcome; it contains two alternatives: stop inspection $\left(S_{n}\right)$ and continue to inspect the remaining all $\left(C_{N}\right)$.

$M\left(Y_{N-n}\right)$ : number of inspections to obtain $Y_{N-n}$ reported "good" items.

$M_{c p}(x, T, n)$ : number of items to compensate producer under supplier's setup $(x, T)$ and producer's sampling size $n$.

\subsection{Problem Description}

Consider a decision problem arising in a two-echelon production process, where the upstream level (or supplier) manufactures a key item and the downstream level (or producer) assembles a product involving this key item. The supplier can select the item production process with a high quality level setup and short cycle time for resetting, but the corresponding total setup cost will be large. On the other hand, if the supplier selects a low quality level with large cycle time, the total setup cost is low, but the risk of returned defective items will be high. Furthermore, for both cases the item quality can be improved if the supplier selects a smaller cycle time of resetting the production process. The problem assumes that the producer bears all inspection cost under its sampling plan, and the supplier undertakes the compensation cost of the returned items.

Figure 1 portrays the problem. When the supplier receives a demand request, he schedules the production process and determines the initial quality setup level " $x$ ", as well as the cycle time " $T$ " to reset the process. A higher initial quality level setup will incur a higher cost, and such will be the same for a shorter cycle time. On the other hand, the downstream producer can take a two-stage rectifying inspection before sending items to its assembly line. Stage 1 determines the sample size, whereas stage 2 chooses between continuing and stopping the remaining items in the lot after the sampling outcome is observed. It is assumed that the inspection 


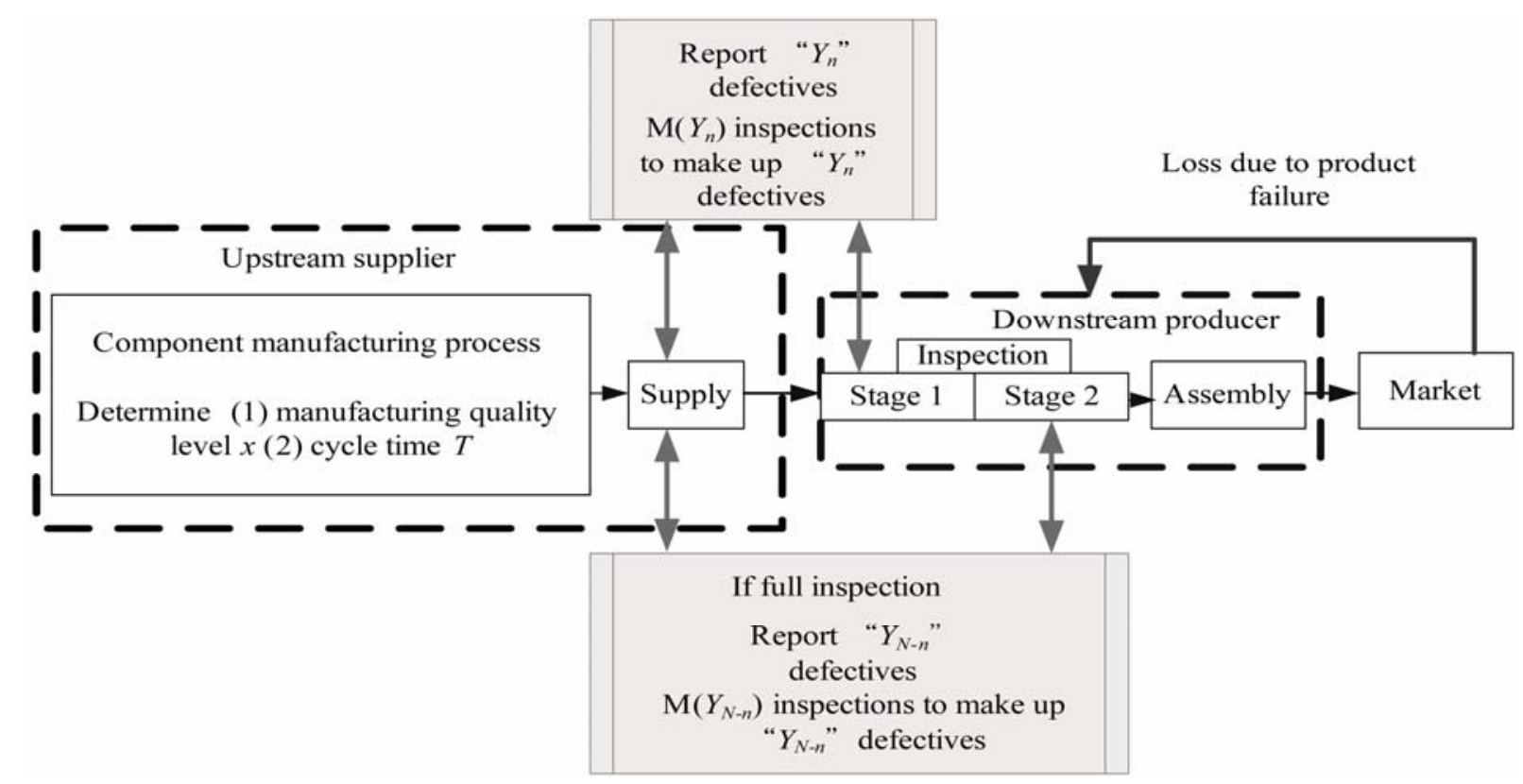

Figure 1. Diagram of the two parties’ decision problem.

will be imperfect; that is, both type I and type II errors may occur. The supplier bears the risk of type I error, whereas the producer may suffer a product failure cost from type II error caused by imperfect inspections. Such types I and II probabilities are treated as constants and can be estimated by data and/or according to production management's discretion. In summary, the supplier's cost includes 1) the quality level setup, 2) the number of such setups, and 3) reimbursement for items reported "defective" by the producer. The producer's cost comprises 1) inspection cost for specified sample size $n$ and extra inspections $M\left(Y_{n}\right)$ for compensation of reported "defective" items, 2) product failure cost due to uninspected defective items and/or inspected items with type II error.

Clearly, the profit-maximizing objectives of the supplier and the producer will conflict. We consider three models in the next section to resolve this conflict.

\subsection{Mathematical Models}

It is assumed that the qualities of items in the lot and items for compensation are statistically independent, and have a common prior distribution. Furthermore, the sampling information can be applied to calculate the posteriors for both types of items.

Let $f_{1}(x, T, N, n)$ denote the profit received by the supplier under its setup decision $(x, T)$, and the producer's decision on the sample size $n$ for the purchase lot of size $N$. Likewise, $f_{2}(x, T, N, n)$ is the profit received by the producer under sample size $n$. Both functions can be expressed as follows.

$$
\begin{aligned}
f_{1}(x, T, N, n)= & \left(S_{u}-C_{u}\right) \cdot N \\
& -C_{x}\left\lceil\frac{N}{T}\right\rceil-E\left[M_{c p}(x, T, n)\right] \cdot C_{u}
\end{aligned}
$$

where $\lceil x\rceil$ is the smallest integer greater than or equal to $x$ and represents the number of production setups for this order, and

$$
\begin{aligned}
E\left[M_{c p}(x, T, n)\right] & =E\left(M\left(Y_{n}\right)\right) \\
& +\sum_{y \in\left\{D_{2}=C_{N}\right\}} E\left(M\left(Y_{N-n}\right) \mid n, y\right) \cdot \operatorname{Pr}\{y \mid n\}
\end{aligned}
$$

is the expected number of additional inspections when the producer's sampling size is $n$. This term includes the extra inspections required to compensate for the reported "defective" items during stage 1 inspection, and the number of reported "defective" items at stage 2 when the stage 2 decision is to continue inspecting the remaining items of the lot (Equation 2).

where $L_{s}=\left(R(n)+Z_{N-n}\right) \cdot k_{2}$ is the loss due to decision " $S_{n}$ ", $L_{C_{N}}=(N-n) \cdot k_{1}+M\left(Y_{N-n}\right) \cdot k_{1}+(R(N)) \cdot k_{2}$ is the loss due to decision " $C_{N}$ ", and $n+E(M(y) \mid n, y)$ is the expected total number of inspections to obtain $n$ reported

$$
f_{2}(x, T, N, n)=\left(S_{d}-C_{u}\right) \cdot N-\sum_{y=0}^{n}\left\{n \cdot k_{1}+M(y) \cdot k_{1}+\operatorname{Min}\left[E\left(L_{S_{n}} \mid n, y\right), E\left(L_{C_{n}} \mid n, y\right)\right]\right\} \cdot \operatorname{Pr}\{y \mid n\}
$$


"good" items given the sampling result $(n, y)$. The producer's optimal sample size $n^{*}$ is the number satisfying Equation (3). Clearly, $f_{2}\left(x, T, N, n^{*}\right)$ is the expected maximum profit that the producer can obtain under quality level setup $(x, T)$.

\section{Model 1: Producer's profit maximization}

In this model, the producer's profit maximization is a constraint (Equation 4) of the supplier's profit optimization problem. In other words, the supplier attempts to maximize its profit by selecting a quality setup $(x, T)$ given that the producer has optimized its own expected profit under $(x, T)$.

$$
\begin{aligned}
& \text { Maximize } f_{1}\left(x, T, N, n_{1}^{*}\right) \\
& x \in X, T \in \Delta \\
& \quad f_{2}\left(x, T, N, n_{1}^{*}\right) \geq f_{2}(x, T, N, n) \text { for } 0 \leq n \leq N
\end{aligned}
$$

\section{Model 2: Supplier's profit maximization}

The supplier's profit is maximized when the producer's sampling size $n$ is 0 ; in such a case there will be no compensation to the producer.

$$
\text { Maximize } \begin{array}{r}
f_{1}(x, T, N, n=0) \\
x \in X, T \in \Delta
\end{array}
$$

Model 3: Collaborative strategy for total profit maximization

$$
\begin{array}{r}
\text { Maximize } f_{1}(x, T, N, n)+f_{2}(x, T, N, n) \\
x \in X, T \in \Delta, 0 \leq n \leq N
\end{array}
$$

This model permits both parties to negotiate the inspection sampling policy to be executed by the producer. This collaborative strategy will yield the maximum total profit as the profit conflict between both sides is minimized.

For any quality setup $(x, T)$ and requested quantity $N$, the following results hold:

1) For Models 1 and 3 :

(1.a) $f_{1}\left(x, T, N, n^{*}\right)+f_{2}\left(x, T, N, n^{*}\right) \geq$ $f_{1}\left(x, T, N, n_{1}^{*}\right)+f_{2}\left(x, T, N, n_{1}^{*}\right)$, where $n^{*}$ is the optimal sample size for Model 3. The reason is that the sample size $n^{*}$ optimizes the combined profit $f_{1}+f_{2}$ within $0 \leq n$ $\leq N$, whereas $n_{1}^{*}$ optimizes $f_{2}$ within $0 \leq n \leq N$.

(1.b) $f_{2}\left(x, T, N, n^{*}\right) \leq f_{2}\left(x, T, N, n_{1}^{*}\right)$,

$f_{1}\left(x, T, N, n^{*}\right) \geq f_{1}\left(x, T, N, n_{1}^{*}\right)$ and $f_{1}\left(x, T, N, n^{*}\right)$

$-f_{1}\left(x, T, N, n_{1}^{*}\right) \geq f_{2}\left(x, T, N, n_{1}^{*}\right)-f_{2}\left(x, T, N, n^{*}\right)$.

2) For Models 2 and 3 : (2.a) $f_{1}\left(x, T, N, n^{*}\right)+f_{2}\left(x, T, N, n^{*}\right) \geq$ $f_{1}(x, T, N, n=0)+f_{2}(x, T, N, n=0)$

(2.b) $f_{1}\left(x, T, N, n^{*}\right) \leq f_{1}(x, T, N, 0)$, $f_{2}\left(x, T, N, n^{*}\right) \geq f_{2}(x, T, N, 0)$ and $f_{2}\left(x, T, N, n^{*}\right)$ $-f_{1}(x, T, N, 0) \geq f_{2}(x, T, N, 0)-f_{2}\left(x, T, N, n^{*}\right)$.

\subsection{Computation Formulae}

The probability that an item is reported as "good" (including type II error) is as follows:

$$
\begin{aligned}
E(W) & =\int_{0}^{1} w \cdot \pi(p) \cdot d p \\
& =\int_{0}^{1}\left[p \cdot q_{1}+(1-p) \cdot\left(1-q_{2}\right)\right] \cdot \pi(p) \cdot d p
\end{aligned}
$$

where $\pi(p)$ is the prior probability density function of an item conforming to quality specification. In our study, $\pi(p)$ is assumed to be Beta $(\alpha, \beta)$. The probability of $y$ reported as "defective” items for $n$ samples is:

$$
\operatorname{Pr}\{y \mid n\}=\int_{0}^{1}\left(\begin{array}{l}
n \\
y
\end{array}\right) \cdot w^{n-y} \cdot(1-w)^{y} \cdot \pi(p) \cdot d p
$$

Other calculations are shown below.

$E(M(y) \mid n, y)=y \cdot \int_{0}^{1} \frac{1}{w} \pi(p \mid n, y) \cdot d p \quad$, where by Bayes' theorem we obtain

$$
\begin{aligned}
& \pi(p \mid n, y)=\frac{\left(\begin{array}{l}
n \\
y
\end{array}\right) \cdot w^{n-y} \cdot(1-w)^{y} \cdot \pi(p)}{\operatorname{Pr}\{y \mid n\}} \\
& E(R(n) \mid n, y)=n \cdot \int_{0}^{1} \frac{(1-p) \cdot\left(1-q_{2}\right)}{\left(p \cdot q_{1}+(1-p) \cdot\left(1-q_{2}\right)\right)} \pi(p \mid n, y) \cdot d p \\
& E\left(Z_{N-n} \mid n, y\right)=(N-n) \cdot(1-E(P \mid n, y)) \\
& E\left(Y_{N-n} \mid n, y\right)=(N-n) \cdot(1-E(W \mid n, y)) \\
& E(W \mid n, y)=\int_{0}^{1} w \cdot \pi(p \mid n, y) \cdot d p \\
& E\left(M\left(Y_{N-n}\right) \mid n, y\right)=(N-n) \cdot E\left(\frac{1}{w} \mid n, y\right)
\end{aligned}
$$

At stage 2, decision " $S_{n}$ " is better than " $C_{N}$ " when $E\left(L_{S_{n}} \mid n, y\right) \leq E\left(L_{C_{n}} \mid n, y\right)$. After algebraic operations, the inequality is converted to

$$
\operatorname{Min}_{0 \leq n \leq N} \sum_{y=0}^{n}\left\{n \cdot k_{1}+E(M(y \mid n, y)) \cdot k_{1}+\operatorname{Min}\left[E\left(L_{S_{n}} \mid n, y\right), E\left(L_{C_{n}} \mid n, y\right)\right]\right\} \cdot \operatorname{Pr}\{y \mid n\}
$$




$$
\frac{1-E(P \mid n, y)-E\left(\frac{(1-P) \cdot\left(1-q_{2}\right)}{P \cdot q_{1}+(1-P) \cdot\left(1-q_{2}\right)} \mid n, y\right)}{E\left(\frac{1}{W} \mid n, y\right)} \leq \frac{k_{1}}{k_{2}}
$$

If there exists an integer $c \geq 0$ such that for all $y>c$ decision $C_{N}$ is better than $S_{n}$, the integer $c$ will be referred to as the critical number of sample size $n$.

\subsection{Process Quality Level Setup and Cycle Time Resetting}

In the problem, it is assumed that the key item engendered in the production process has the following property: once a defective item is produced, all items following the first defective one will also be defective. Interrupted geometric (IG) distribution meets the item quality for such a production environment. A short time replacement policy of production equipment (resetting) will result in a high process yield; however, the item quality enhancement will be costly when the lot size is large.

For IG, let $r_{x}$ represent the yield of the first item with respect to $x$ quality level setup. Thus, the probability of $t$ non-defective items under cycle time $T$ will be $\operatorname{Pr}\left\{G_{T}=t\right\}$ $=r_{x}^{t} \cdot\left(1-r_{x}\right), t=0,2, \ldots, T-1 ; \operatorname{Pr}\left\{G_{T}=T\right\}=\operatorname{Pr}\left\{G_{T} \geq T\right\}$ $=r_{x}^{T}$. Here we assume that each item takes one unit of time to produce.

The average and variance of yield for cycle time $T$ are as follows:

$$
\begin{gathered}
E\left(G_{T} / T\right)=\left(\frac{r-r^{T+1}}{1-r}\right) / T \\
\operatorname{Var}\left(G_{T} / T\right)=\operatorname{Var}\left(G_{T}\right) / T^{2} \\
=\left[r^{2} \cdot\left(\frac{1-r^{T}}{(1-r)^{2}}-\frac{T \cdot r^{T}}{1-r}\right)-T \cdot r^{T+1}\right] / T^{2}
\end{gathered}
$$

For a lot size $N=M \cdot T$, the process will perform $M$ setups to produce $N$ items. Let $\left(G_{T}^{1}, \cdots, G_{T}^{M}\right)$ be the number of conforming items under $M$ setups with cycle time $T$. The expected yield will be the same as (9), but the variance becomes

$$
\operatorname{Var}\left[\left(G_{T}^{1}+G_{T}^{2}+\ldots+G_{T}^{M}\right) /(T \cdot M)\right]=\operatorname{Var}\left(G_{T}^{1}\right) /\left(T^{2} \cdot M\right)
$$

Suppose that the supplier only provides the producer with information on the mean and variance of the key item's quality; if the producer selects Beta $(\alpha, \beta)$ as the prior distribution for the output yield, the parameters $\alpha$ and $\beta$ can be estimated by

$$
\begin{gathered}
E(P)=E\left(G_{T}^{1}\right) / T=\frac{\alpha}{\alpha+\beta} \text { and } \\
\operatorname{Var}(P)=\operatorname{Var}\left(G_{T}^{1}\right) /\left(T^{2} \cdot M\right)=\frac{\alpha \cdot \beta}{(\alpha+\beta)^{2} \cdot(\alpha+\beta+1)}
\end{gathered}
$$

\section{Illustrative Example}

The profit sharing models are illustrated through an example with the following parameters: $k_{1}=12, k_{2}=150, C_{u}=$ 120, $N=1500, S_{u}=180, S_{d}=230$, two possibilities of process quality setups: $X=\left\{r_{x} \mid 0.995,0998\right\}$, the set of resetting cycle times: $\Delta=\{T \mid 10,15,20,25,30\}$, and three cases of inspection quality levels: one of which is error-free $\left(q_{1}, q_{2}\right)=(1.0,1.0)$, and the other two are with minor errors: $\left(q_{1}, q_{2}\right)=(0.98,0.98)$ and $(0.96,0.96)$. As aforementioned, the producer will obtain the mean and variance of the yield regarding the lot of size $N$. The producer adopts a Beta prior distribution to represent the lot quality and for sampling inspection. Table 1 presents the information on yield, $E(P)$ and $\operatorname{Var}(P)$, which are derived from Equations (9), (10) and (11). This information will in turn be used to estimate the parameters $(\alpha, \beta)$ of Beta prior according to Equations (12) and (13). The results indicate that a shorter cycle time $T$ leads to a higher item quality and smaller variance. The resulting Beta prior will then be incorporated with $\left(q_{1}, q_{2}\right)$ to calculate "reported good" probability $E(W)$ using equation (7). Table 2 displays the probabilities of "reported good" for all possible combinations of $\left\{r_{x}, T,\left(q_{1}, q_{2}\right)\right\}$. The higher the value of $\left(q_{1}, q_{2}\right)$, the larger the probability of "reported good".

Table 3 shows the numerical results of the three models when $T=15$ and $N=1500$ with three different $\left(q_{1}, q_{2}\right)$ values. The calculation uses the following quality setup costs: $C_{x}=450$ for $r_{x}=0.995$, and $C_{x}=500$ for $r_{x}=0998$. Generally, when there are inspection errors, reported defective probability $1-E(W)$ increases as the value of $\left(q_{1}, q_{2}\right)$ decreases. The producer will nonetheless receive maximum profit in Model 1 as its risk of delivering defective products to customers is minimized. However, the supplier will receive minimum benefit if he complies with Model 1. In contrast, the supplier's profit will be maximized in Model 2, since he has no obligation for any defective items sent to the producer. Here, the producer's interest is reduced to the minimum. In Model 3, the benefits of both parties are between Models 1 and 2, but their combined profit is the highest. In the case of $T=15$ and $N=1500$, the optimal decisions $\left(r_{x}, n^{*}, c^{*}\right)$ are $(0.995,18,0),(0.998,12,0),(0.998,10,1)$ for $\left(q_{1}, q_{2}\right)=$ $(0.96,0.96),(0.98,0.98)$ and $(1.0,1.0)$, respectively. It appears that for any model, the profit of either party decreases as true yield $E(P), q_{1}$, and $q_{2}$ decrease. The 
Table 1. Item quality using interrupted geometric distributions.

\begin{tabular}{|c|c|c|c|c|c|c|}
\hline$N=1500$ & $T$ & $E\left(G_{T}\right)$ & $M$ & $E(P)$ & $\operatorname{Var}(p)$ & $\operatorname{Beta}(\alpha, \beta)$ \\
\hline \multirow{5}{*}{$r_{x}=0.995$} & 10 & 150 & 9.73 & 0.973 & 0.0064 & $(3.02,0.084)$ \\
\hline & 15 & 100 & 14.41 & 0.961 & 0.0094 & $(2.84,0.115)$ \\
\hline & 20 & 75 & 18.98 & 0.949 & 0.0124 & $(2.75,0.148)$ \\
\hline & 25 & 60 & 23.44 & 0.938 & 0.0153 & $(2.61,0.177)$ \\
\hline & 30 & 50 & 27.78 & 0.922 & 0.0181 & $(2.76,0.235)$ \\
\hline \multirow{5}{*}{$r_{x}=0.998$} & 10 & 150 & 9.89 & 0.989 & 0.0065 & $(0.66,0.074)$ \\
\hline & 15 & 100 & 14.76 & 0.984 & 0.0097 & $(0.61,0.010)$ \\
\hline & 20 & 75 & 19.58 & 0.949 & 0.0129 & $(0.58,0.0124)$ \\
\hline & 25 & 60 & 24.36 & 0.974 & 0.0161 & $(0.53,0.014)$ \\
\hline & 30 & 50 & 29.09 & 0.970 & 0.0192 & $(0.52,0.016)$ \\
\hline
\end{tabular}

Table 2. Probability of being reported "good" for various $\left\{r_{x}, T,\left(q_{1}, q_{2}\right)\right\}$.

\begin{tabular}{|c|c|c|c|c|}
\hline$N=1500$ & $T$ & $\left(q_{1}, q_{2}\right)=(1,1) E(W)$ & $\left(q_{1}, q_{2}\right)=(0.98,0.98) E(W)$ & $\left(q_{1}, q_{2}\right)=(0.96,0.96) E(W)$ \\
\hline \multirow{5}{*}{$r_{x}=0.995$} & 10 & 0.973 & 0.954 & 0.935 \\
\hline & 15 & 0.961 & 0.943 & 0.924 \\
\hline & 20 & 0.949 & 0.931 & 0.913 \\
\hline & 25 & 0.938 & 0.920 & 0.903 \\
\hline & 30 & 0.922 & 0.905 & 0.888 \\
\hline \multirow{5}{*}{$r_{x}=0.998$} & 10 & 0.989 & 0.969 & 0.950 \\
\hline & 15 & 0.984 & 0.965 & 0.945 \\
\hline & 20 & 0.979 & 0.960 & 0.941 \\
\hline & 25 & 0.974 & 0.955 & 0.936 \\
\hline & 30 & 0.970 & 0.951 & 0.932 \\
\hline
\end{tabular}

Table 3. Numerical results of three models when $T=15, N=1500, C_{x}=\{450,500\}$.

\begin{tabular}{|c|c|c|c|c|c|c|}
\hline \multirow[b]{2}{*}{$q^{1} \& q^{2}$} & \multicolumn{3}{|c|}{$r_{x}=0.995\left(C_{x}=450\right)$} & \multicolumn{3}{|c|}{$r_{x}=0.998\left(C_{x}=500\right)$} \\
\hline & 0.96 & 0.98 & 1.0 & 0.96 & 0.98 & 1.0 \\
\hline $\mathrm{E}(W)$ & 0.924 & 0.943 & 0.961 & 0.945 & 0.965 & 0.984 \\
\hline Model 1-Supplier's proift & 44.045 & 44.410 & 44.778 & 39.579 & 39.883 & 39.998 \\
\hline Producer's profit & 59.445 & 61.357 & 65,921 & 62.349 & 66.929 & 71.924 \\
\hline Pptimal sample size $n^{*}$ & 93 & 87 & 84 & 86 & 64 & 10 \\
\hline Critical number $c^{*}$ & 5 & 5 & 4 & 4 & 2 & 1 \\
\hline Total profit & 103.490 & 105.767 & 110.699 & 101.928 & 106.812 & 111.922 \\
\hline Model 2-Supplier's profit & 45.000 & 45.000 & 45.000 & 40.000 & 40.000 & 40.000 \\
\hline Producer's profit & 57.277 & 61.076 & 64.806 & 61.218 & 65.076 & 69.433 \\
\hline Total profit & 102.277 & 106.076 & 109.806 & 101.218 & 105.076 & 109.433 \\
\hline Model 3-Supplier's profit & 44.972 & 44.985 & 44.994 & 44.988 & 39.996 & 39.998 \\
\hline Producer’s profit & 58.783 & 61.281 & 65.819 & 62.053 & 66.834 & 71.924 \\
\hline Optimal sample size $n^{*}$ & 18 & 16 & 15 & 16 & 12 & 10 \\
\hline Critical number $c^{*}$ & 0 & 0 & 1 & 0 & 0 & 1 \\
\hline Total profit & 103.755 & 106.266 & 110.813 & 102.041 & 106.830 & 111.922 \\
\hline
\end{tabular}


Table 4. Numerical results of Model 3 when $C_{x}=(175,200)$ for $r_{x}=(0995,0.998)$ and $N=1500$.

\begin{tabular}{|c|c|c|c|c|c|c|}
\hline $\begin{array}{r}r_{x} \\
T\end{array}$ & & $\begin{array}{c}10 \\
(M=150)\end{array}$ & $\begin{array}{c}15 \\
(\mathrm{M}=100)\end{array}$ & $\begin{array}{c}20 \\
(M=75)\end{array}$ & $\begin{array}{c}25 \\
(M=60)\end{array}$ & $\begin{array}{c}30 \\
(M=50)\end{array}$ \\
\hline \multirow{4}{*}{$r_{x}=0.995$} & $\left(n^{*}, c^{*}\right)$ & $(10,0)$ & $(16,0)$ & $(21,1)$ & $(24,1)$ & $(27,1)$ \\
\hline & $f_{1}$ & 59,992 & 69,985 & 74,591 & 77,219 & 84,311 \\
\hline & $f_{2}$ & 69,938 & 61,281 & 58,795 & 56,709 & 55,841 \\
\hline & $f_{1}+f_{2}$ & 123,930 & 131,267 & 133,386 & 133,928 & 135,152 \\
\hline \multirow{4}{*}{$r_{x}=0.998$} & $\left(n^{*}, c^{*}\right)$ & $(1,0)$ & $(12,0)$ & $(13,0)$ & $(15,0)$ & $(15,0)$ \\
\hline & $f_{1}$ & 59,997 & 69,996 & 74,986 & 77,596 & 79,772 \\
\hline & $f_{2}$ & 66,996 & 66,834 & 66,061 & 63,864 & 61533 \\
\hline & $f_{1}+f_{2}$ & 126,993 & 136,830 & 141,047 & 141,460 & 141,305 \\
\hline
\end{tabular}

Table 5. Numerical results for two different quality setup costs.

\begin{tabular}{|c|c|c|c|c|c|c|}
\hline \multicolumn{2}{|c|}{ Setup cost and profits } & $\begin{array}{c}\mathrm{T}=10 \\
(M=150)\end{array}$ & $\begin{array}{c}\mathrm{T}=15 \\
(M=100)\end{array}$ & $\begin{array}{c}\mathrm{T}=20 \\
(M=75)\end{array}$ & $\begin{array}{c}\mathrm{T}=25 \\
(M=60)\end{array}$ & $\begin{array}{c}\mathrm{T}=30 \\
(M=50)\end{array}$ \\
\hline \multirow{3}{*}{$C_{x}=90 r_{x}=0.995$} & $f_{1}$ & 76,492 & 80,985 & 82,841 & 83,819 & 84,811 \\
\hline & $f_{2}$ & 63,938 & 61,281 & 58,795 & 56,709 & 55,814 \\
\hline & $f_{1}+f_{2}$ & 140,420 & 142,266 & 141,636 & 140,528 & 140,652 \\
\hline \multirow{3}{*}{$C_{x}=100 r_{x}=0.998$} & $f_{1}$ & 74,997 & 79,996 & 82,846 & 83,596 & 84,811 \\
\hline & $f_{2}$ & 66,996 & 66,834 & 66,061 & 63,864 & 55,841 \\
\hline & $f_{1}+f_{2}$ & 141,193 & 146,830 & 148,547 & 147,460 & 146,305 \\
\hline \multirow{3}{*}{$C_{x}=400 r_{x}=0.995$} & $f_{1}$ & 29,492 & 39,985 & 59,591 & 65,219 & 69,311 \\
\hline & $f_{2}$ & 63,938 & 61,281 & 58,795 & 56,709 & 55,841 \\
\hline & $f_{1}+f_{2}$ & 93,490 & 111,266 & 118,386 & 121,928 & 125,152 \\
\hline \multirow{3}{*}{$C_{x}=500 r_{x}=0.998$} & $f_{1}$ & 14,992 & 39,985 & 52,486 & 59,596 & 64,772 \\
\hline & $f_{2}$ & 66,996 & 66,834 & 66,061 & 63,864 & 51,533 \\
\hline & $f_{1}+f_{2}$ & 81,993 & 106,830 & 118,547 & 123,460 & 126,305 \\
\hline
\end{tabular}

decrease of $q_{1}$ will raise cost for both parties due to type 1 risk error. In this situation, the supplier will be required to deliver additional items to the producer, and the producer will also incur additional inspection cost. Furthermore, if $q_{2}$ decreases, the producer will face increased risk of delivering more failed products to its customers. In practice, the penalty cost of delivering a failed product is regarded as much greater than the unit inspection cost. Another impact of the $\left(q_{1}, q_{2}\right)$ decrease is the increased stringency of the inspection sampling plan. The inspection sample size will be enlarged.

A larger setup cost will lead to higher item quality. For the supplier, there is a trade-off between item quality and setup cost/cycle time. Table 4 shows the numerical results of Model 3 when $C_{x}=(175,200)$ for $r_{x}=$ $(0.995,0.998)$. The optimal decision of this scenario is $\left\{r_{x}\right.$, $\left.T,\left(n^{*}, c^{*}\right)\right\}=(0.998,25,(15,0))$. Table 5 presents additional results of other values $C_{x}$ for $r_{x}$. When $C_{x}=(90$, $100)$ for $r_{x}=(0.995,0.998)$, the optimal decision is $\left(r_{x}, T\right)$
$=(0.998,20)$ with a total profit of 148,547 , and when $C_{x}$ $=(400,500)$, the optimal decision is $\left(r_{x}, T\right)=(0.998,30)$, which will yield a total profit of 126,305.

Model 1 is appropriate when the producer is a major purchaser of the key item; on the other hand, Model 2 may be more suited when the supplier is an exclusive input source of the key item. Often in practice however, both parties will not completely agree on either Model 1 or Model 2. A compromising solution would involve both parties utilizing Model 3, and the supplier determining the best setup of $\left(C_{x}, T\right)$ that leads to the maximum combined profit. Then each party will receive his own share according to the solution. Nevertheless, further negotiation on profit sharing may be needed if one party claims that he contributed more towards the combined profit.

\section{Conclusions}

This study discusses a decision-making problem on the 
profit sharing of a key item in a two-echelon supply chain process. The upstream supplier determines the quality level, as well as the reset cycle time, during the manufacturing process. However, the producer aims to minimize his risk by selecting and implementing an optimal inspection decision. Since the two parties have conflicting interests, three profit sharing models are proposed to resolve the conflict. Model 1 allows the producer to reduce his risk to the minimum level, whereas Model 2 will work solely to the supplier's favor. Model 1 will be useful if the producer's penalty cost of product failure is high. On the other hand, Model 2 is more applicable if the supplier provides high quality key items, or is the dominant source of the key item. These two models tend to be more one-sided, situation-based solutions that lopsidedly favor either the supplier or producer. Model 3 may be the most practical and compromising one, as it requires both parties to work together in obtaining the largest sum of profits, and prevents an unreasonably large gap between their individual profits. This collaborative manufacturing strategy can ensure that both parties receive acceptable returns and maintain long-term business cooperation.

\section{Acknowledgements}

This work was supported by the National Science Council in Taiwan under grant NSC 96-2628-E155-006.

\section{REFERENCES}

[1] G. B. Wetherill and W. K. Chiu, "A Review of Acceptance Sampling Schemes with Emphasis on the Economic Aspect,” International Statistical Review, Vol. 43, No. 2, 1975, pp. 91-210.

[2] S. Bisgaard, W. G. Hunter and L. Pallesen, "Economic Selection of Quality of Manufactured Product," Technometrics, Vol. 26, No. 1, 1984, pp. 9-18.

[3] D. Y. Golhar, "Determination of the Best Mean Contents for a Canning Problem,” Journal of Quality Technology, Vol. 19, No. 2, 1987, pp. 82-84.

[4] H. Moskowitz and K. Tang, "Bayesian Variables Acceptance-Sampling Plans: Quadratic Loss Function and StepLoss Function,” Technometrics, Vol. 34, No. 3, 1992, pp. 340-347.

[5] R. L. Fink and T. M. Margavio, "Economic Models for Single Sample Acceptance Sampling Plans, No Inspection, and 100 Percent Inspection,” Decision Sciences, Vol. 25, No. 4, 1994, pp. 625-653.

[6] M. S. Aminzadeh, "Bayesian Economic Variable Acceptance-Sampling Plan Using Inverse Gaussian Model and Step-Loss Function," Communication in Statistics - Theory and Methods, Vol. 32, No. 5, 2003, pp. 961-982.
[7] M. K. Lee, S. H. Hong and E. A. Elsayed, "The Optimum Target Value under Single and Two-Stage Screenings,” Journal of Quality Technology, Vol. 33, No. 4, 2001, pp. 506-514.

[8] M. K. Lee and E. A. Elsayed, "Process Mean and Screening Limits for Filling Processes under Two-Stage Scr- eening Procedure,” European Journal of Operation Research, Vol. 138, No. 1, 2002, pp.118-126.

[9] H. M. Hsu, T. S. Su, M. -C. Wu and L. -C. Huang, "Multiple Lot-Sizing Decisions with an Interrupted Geometric Yield and Variable Production Time," Computers and Industrial Engineering, Vol. 57, No. 3, 2009, pp. 699706.

[10] R. H. Yeh, W. T. Ho and S.T. Tseng, "Optimal Production Run Length for Products Sold with Warranty," European Journal of Operational Research, Vol. 120, No. 3, 2000, pp. 575-582.

[11] M. Ben-Daya and M. Hariga, "Economic Lot Scheduling Problem with Imperfect Production Processes," The Journal of the Operational Research Society, Vol. 51, No. 7, 2000, pp. 875-881.

[12] I. Moon, B. C. Giri and K. Choi, "Economic Lot Scheduling Problem with Imperfect Production Processes and Setup Times," The Journal of the Operational Research Society, Vol. 53, No. 6, 2002, pp. 620-629.

[13] C. H. Wang and S. H. Sheu, "Optimal Lot Sizing for Products Sold under Free-Repair Warranty,” European Journal of Operational Research, Vol. 149, No. 1, 2003, pp. 131-141.

[14] C. H. Wang, “The Impact of a Free-Repair Warranty Policy on EMQ Model for Imperfect Production Systems," Computers \& Operations Research, Vol. 31, No. 12, 2004, pp. 2021-2035.

[15] S. Anily, "Single-Machine Lot-Sizing with Uniform Yields and Rigid Demands: Robustness of the Optimal Solution," IIE Transactions, Vol. 27, No. 5, 1995, pp. 625-633.

[16] D. W. Pentico, “An Evaluation and Proposed Modification of the Sepehri-Silver-New Heuristic for Multiple Lot Sizing under Variable Yield," IIE Transactions, Vol. 20, No. 4, 1988, pp. 360-363.

[17] S. Anily, A. Beja and A. Mendel, "Optimal Lot Sizes with Geometric Production Yield and Rigid Demand," Operations Research, Vol. 50, No. 3, 2002, pp. 424-432.

[18] A. X. Zhang and S. M. Guu, "The Multiple Lot Sizing Problem with Rigid Demand and Interrupted Geometric Yield,” IEE Transactions, Vol. 30, No. 1, 1998, pp. 427431.

[19] S. M. Guu and A. X. Zhang, "The Finite Multiple Lot Sizing Problem with Interrupted Geometric Yield and Holding Costs," European Journal of Operational Research, Vol. 145, No. 3, 2003, pp. 635-644. 